\title{
J.L.R. LEDEGANG-KEEGSTRA, Le Passavant de Bèze et le Cinquiesme Livre de Rabelais
}

\section{Filippo Fonio}

\section{(2) OpenEdition}

\section{Journals}

\section{Edizione digitale}

URL: http://journals.openedition.org/studifrancesi/33008

DOI: 10.4000/studifrancesi.33008

ISSN: 2427-5856

\section{Editore}

Rosenberg \& Sellier

\section{Edizione cartacea}

Data di pubblicazione: 1 décembre 2005

Paginazione: 626

ISSN: 0039-2944

\section{Notizia bibliografica digitale}

Filippo Fonio, «J.L.R. Ledegang-Keegstra, Le Passavant de Bèze et le Cinquiesme Livre de Rabelais», Studi Francesi [Online], 147 (XLX | III) | 2005, online dal 01 novembre 2015, consultato il 19 avril 2021. URL: http://journals.openedition.org/studifrancesi/33008; DOI: https://doi.org/10.4000/studifrancesi. 33008

Questo documento è stato generato automaticamente il 19 avril 2021.

\section{(c) (i) (9)}

Studi Francesi è distribuita con Licenza Creative Commons Attribuzione - Non commerciale - Non opere derivate 4.0 Internazionale. 


\title{
J.L.R. LEDEGANG-KEEGSTRA, Le Passavant de Bèze et le Cinquiesme Livre de Rabelais
}

\author{
Filippo Fonio
}

\section{NOTIZIA}

J.L.R. LEDEGANG-KEEGSTRA, Le Passavant de Bèze et le Cinquiesme Livre de Rabelais, «Bibliothèque d'Humanisme et Renaissance», LXVI, 2 (2004), pp. 381-385.

1 A partire dai contributi di Charles Bost, e da quelli più recenti di Mireille Huchon, è stata riconosciuta l'affinità di ispirazione fra il Cinquiesme Livre di Rabelais, in particolare la prima parte, L'Isle Sonante (1562), e Le Passavant (1553) di Théodore de Bèze, satira in latino maccheronico e in forma di epistola rivolta contro Pierre Lizet. Lo studio in questione propone una serie di raffronti intertestuali fra Rabelais e Bèze, sulla base delle considerazioni di Le Duchat, primo editore moderno di Rabelais, il quale ipotizzava che Bèze conoscesse i brouillons poi assemblati a costituire il Cinquiesme Livre, rabelaisiano o presunto tale. 